\title{
Effect of Work Environment on Level of Work Stress and Burnout among Nurses in a Teaching Hospital in Nigeria
}

\author{
Guobadia Pauline Ojekou1, Odetola Titilayo Dorothy ${ }^{2 *}$ \\ ${ }^{1}$ School of Occupational Health Nursing, University College Hospital, Ibadan, Nigeria \\ ${ }^{2}$ Department of Nursing, University of Ibadan, Ibadan, Nigeria \\ Email: paulineguobadia@yahoo.com,
}

Received 27 July 2015; accepted 27 October 2015; published 30 October 2015

Copyright (C) 2015 by authors and Scientific Research Publishing Inc.

This work is licensed under the Creative Commons Attribution International License (CC BY). http://creativecommons.org/licenses/by/4.0/

(c) (i) Open Access

\begin{abstract}
Nurses' roles expose them to a lot of stress based upon the physical labour, exposure to human suffering, lengthy work hours, poor staffing, and interpersonal relationships that are central to the work they do. Nurses are expected to deliver humane, empathetic, culturally-sensitive and proficient care in working environments with limited resources and increasing responsibilities. Such imbalance between providing high quality care with limited resources leads to physical and mental stress. This stressful nature of nursing can ultimately lead to job dissatisfaction and burnout which among health care providers are important issues since they affect turnover rates, staff retention and ultimately the quality of patient care. A thoroughly validated self developed questionnaire with a reliability coefficient of 0.78 was used to explore the effect of work environment on the level of work stress and burnout among nurses. A purposive sampling technique was utilized to select 100 participants from the medical unit of the hospital. Three hypotheses were tested at a significant level of 0.05. Data were analyzed using ANOVA and Pearson's Correlation. The study revealed that level of stress was higher among the staff nurses who had worked for only between 0 and 3 years, with mean stress score 46.0000. Findings further revealed that as the cadre rose, the nurses assumed that managerial roles were accountable for increased subordinates and oversee health related and administrative responsibilities and they experienced more stress. Also there is a significant relationship among work environment, stress and burnout among the nurses in the selected unit. In conclusion, though work conditions and environment are not favourable, there are job security and good interpersonal relationship among the nurses which cushion the stressful situations. It is therefore recommended that the management of the hospitals should provide a conducive work environment, providing necessary resources and adequate break periods to ensure staff welfare.
\end{abstract}

${ }^{*}$ Corresponding author.

How to cite this paper: Ojekou, G.P. and Dorothy, O.T. (2015) Effect of Work Environment on Level of Work Stress and Burnout among Nurses in a Teaching Hospital in Nigeria. Open Journal of Nursing, 5, 948-955.

http://dx.doi.org/10.4236/ojn.2015.510100 


\section{Keywords}

\section{Work Environment, Stress, Burnout, Nurses}

\section{Introduction}

Every work environment especially within a hospital setup needs to be conducive, friendly and stress free to promote quality care and wellbeing of health care workers whose job demands are increasing day by day. This is as a result of advancement in technology and patient's demand for quality in response to increasing health care cost. Stress is considered a normal part of life which is necessary occasionally as a push to increasing functional capacity, but when it is experienced over a prolonged period it becomes detrimental to health leading to a decline in productivity [1].

Stress can be defined as a particular relationship between the person and the environment that is assessed by the person as taxing or exceeding his or her resources and endangering his or her well-being [2]. Stress on its own does not have any damaging effect on an individual; however individuals' assessment of an event, their perceptions and interpretations give meaning and their coping ability determines whether events are viewed as threatening or positive. Personality traits also influence individual reaction to stress because what may be strenuous to one person may be stimulating to another [3].

As far back as the mid-1950s, stress was regarded as an occupational hazard and occupational stress cited as a significant health problem [4] while in the 1960s, patient's care, decision making, taking responsibility, and change were identified as sources of anxiety among nurses which predisposed them to work stress [5]. Nurse's role has long been regarded as stress-filled based upon the physical labor, human suffering, work hours, staffing, and interpersonal relationships that are central to what the work nurses do [6]. This stressful nature of nursing can ultimately lead to job dissatisfaction and burnout [7]. This statement is in line with some studies which conclude that the provision of health care services is demanding both physically and psychologically [8]. Nursing occupies a conspicuous position among the professions that have been identified as the most stressful worldwide as nurses relate with humans mostly in times of pain, suffering and death [6]. Nurses work tirelessly rendering care to critically and chronically ill patients who are between life and death in an environment where there is lack of tolerance for error [9]; all these can exert intense psychological and physical pressures on the health care giver leading to stress or burnout syndrome.

Among health care professionals, nurses have been found to be most prone to burnout [10]. This is more so because nurses are expected to deliver humane, empathetic, culturally sensitive, proficient and moral care, in working environments with limited resources, reduced supply of nurses and increasing responsibilities. Such imbalance between providing high quality care within an environment of limited resources leads to stress [11].

Job satisfaction and burnout among health care providers are important issues since they affect turnover rates, staff retention and ultimately the quality of patient care [12]. Burnout has been defined as "a syndrome of physical and emotional exhaustion, involving the development of stress which can lead to the development of negative self-concept, negative job attitudes and loss of concern for clients". Burnout has also been associated with high employment turnover, excessive absenteeism, negative job attitudes, low morale and a reduction in willingness to help others [10].

The way that an individual views and processes stress determines how much stress is felt and how close the person is to burnout. Perceptions of job stress and burnout are not just a product of work conditions because not all workers, exposed to the same conditions, develop burnout or perceive stress [3]. An individual can be exposed to few stressors but be unable to process the stress well and thus experience burnout. Another person, however, can be exposed to a significant amount of stressors, but process each well, and avoid burnout. How close a person is to a state of burnout is greatly dependent on individual differences [13].

According to psychological theories, stress is determined by the balance between the perceived demands from the environment and the individual's resources to meet those demands [14].

The International Council of Nurses (ICN) (2008) [15] declares that nurses, doctors, and laboratory technicians experience the highest job related stress with 45 percent reporting that their jobs are quite or extremely stressful. Likewise, the International Labour Organization has identified nursing as an industry with relatively 
high level of stress and burnout [16]. Stress can contribute to human errors and accidents.

\section{Methodology}

The study utilized a descriptive design to explore the role of work environment and conditions on the level of work stress and burnout among nurses in medical unit of University College Hospital (UCH) The Medical Unit is made up of 7 wards, rendering nursing care to both male and female clients on admission in the hospital receiving medical and long term care for acute and mostly chronic illness that does not require surgical intervention. The wards under the medical unit include: West Three ward, South West Three, Central Ward 3rd, East Three, South East Three, East Two and Multi-Drug Resistant Ward.

\subsection{Study Population}

The study population consisted of all professional nurses who are directly involved in patient care in the Medical Unit of University College Hospital, Ibadan. The professional nurses ranged between the cadres of Staff Nurse to Chief Nursing Officer.

\subsection{Study Design}

It was a descriptive study which utilized a convenience sampling technique to select all available and willing Registered nurses from each ward in the unit, making a total of 100 registered nurses.

\subsection{Sample Size Determination}

The sample size for this study was determined using sample size formula below [17]:

$$
n=\frac{t_{2} \times P(1-P)}{m^{2}}
$$

where

$n=$ Required sample size;

$t=$ confidence level at $95 \%=1.96$;

$P=$ Estimated population of professional nurses carrying out direct patient care in the medical unit $=80$ out of a total nursing population of $1080=0.07$;

$m=$ margin of error tolerance at $5 \%=0.05$.

Sample size $n=\frac{1.96^{2} \times 0.07(1-0.07)}{m^{2}}=\frac{3.84 \times 0.07(1-0.07)}{0.05^{2}}=\frac{0.249984}{0.0025}=99.99$.

Calculated sample size 100 .

$10 \%$ of calculated sample size $=10$ added to make up for attrition.

Total number of respondents $=110$.

\subsection{Sampling Technique}

A purposive sampling technique was adopted. This implies that all the nurses who are directly involved in nursing care of the patients on all the wards of the Medical Unit ranging between the cadres of Staff nurses and Chief Nursing Officers were included in the study.

The calculated sample size was 100 . Since 100 was the minimum sample size that can be studied, the researcher decided to increase the power of significance by including all the nurses in the Medical Unit who are involved in direct nursing care of patients and are willing to participate in the study in the sample frame, they were 110 .

According to Suresh and Chandrashekara (2012) [18], determining the optimal sample size for a study assures an adequate power to detect statistical significance and that power proportionately increases as the sample size for study increases.

\subsection{Exclusion Criteria}

Professional nurses who are at the managerial post of Assistant Directors of Nursing as they are mostly on ad- 
ministrative schedule and are not directly involved in nursing care of the patients on the ward.

\subsection{Ethical Consideration}

The need for the research and procedure for data collection was explained to the participants. Verbal consent was obtained from participant to participate in the study. They were informed that participation was entirely voluntary, confidential and anonymous.

\subsection{Instrument for Data Collection}

The self-developed questionnaire was used to cover demographic characteristics, factors relating to job related stress from the work environment, work conditions and effect of stress on health. The instrument was trialtested on 20 nurses in the medical unit of the State Hospital in Ibadan and the results had a co-efficient of 0.78 . Showing that among similar groups, the questionnaire will consistently test and answer what it is meant for. Necessary corrections were made and the questionnaire was administered without any bias among the study population.

The researcher visited the wards in the selected unit of the hospital to serve the questionnaire personally to nurses who are willing to participate in the study, 110 questionnaires were served as some of the nurses were not around. Only 104 questionnaires were retrieved out of which only 100 were well filled the remaining 4 questionnaire were not adequately filled and could not be analyzed therefore were discarded.

The quantitative data was analyzed through content analysis. The responses were sorted out and grouped into similar and non similar responses

Comments were categorized and presented in simple percentages.

Hypotheses were tested using Analysis of Variance (ANOVA) and Pearson Correlation to relate work condition and work environment to stress and burnout among the nurses.

\section{Results}

The results are presented based on the objectives and hypotheses

\section{Discussion}

This study has revealed an either way relationship between work environment level of work stress and burnout among nurses. This is shown in Table 1 and Table 2. Table 1 shows a significant relationship between work environment and incidence of stress among nurses while Table 2 indicated that there is no significant relationship between work condition and stress among nurses. This is also supported by Table 3 and Table 4. Table 3 shows that work environment is not too conducive, leading to stress while Table 4 presented $69 \%$ of the res-

Table 1. Showing relationship between work environment and incidence of stress among nurses. For hypotheses 2 Pearson Correlation was used to relate stress and burnout to work environment.

\begin{tabular}{ccc}
\hline & Stress & Remark \\
Work environment: Pearson correlation & 0.351 & 0.000 \\
Sig. (2-tailed) & 100 & Significant \\
\hline
\end{tabular}

The results showed a positive correlation 0.351 , the significance (2-tailed) is 0.000 in total respondents numbering 100 . Correlation is significant at the 0.01 level ( 2 tailed), 0.000 is $<0.01$, this means that there is a significant relationship between work environment and stress and burnout among the nurses.

Table 2. Showing relationship between work condition and stress among nurses. For hypotheses 3 pearson correlation was used to relate stress and burnout to work conditions.

\begin{tabular}{lcc}
\hline Work condition: Pearson correlation & -0.033 & Not \\
Sig. (2-tailed) & 0.745 & 100 \\
No. & Significant &
\end{tabular}

Looking at work conditions, there is a negative correlation -0.033 , the significance (2-tailed) is 0.745 in a total respondents numbering 100.0 .745 is $>0.01$, this means that there is no relationship between work conditions and stress and burnout among the nurses. 
Table 3. Showing factors relating to job related stress from work environment.

\begin{tabular}{lccccc}
\hline & $\begin{array}{c}\text { Always } \\
\text { present }\end{array}$ & $\begin{array}{c}\text { Often } \\
\text { present }\end{array}$ & $\begin{array}{c}\text { Rarely } \\
\text { present }\end{array}$ & $\begin{array}{c}\text { Not } \\
\text { present }\end{array}$ & Total \\
\hline Excessive noise disturbing my work on the ward & $69(69 \%)$ & $20(20 \%)$ & $9(9 \%)$ & $2(2 \%)$ & $100 \%$ \\
$\begin{array}{l}\text { Movement and interruptions from medical, para-medical and visitors } \\
\text { disturbing my work on the ward }\end{array}$ & $58(58 \%)$ & $34(34 \%)$ & $6(6 \%)$ & $2(2 \%)$ & $100 \%$ \\
Adequate lighting both day and night on the ward to promote work & $8(8 \%)$ & $85(85 \%)$ & $6(6 \%)$ & $2(2 \%)$ & $100 \%$ \\
Adequate provision of privacy for procedures on the ward & $12(12 \%)$ & $81(81 \%)$ & $5(5 \%)$ & $2(2 \%)$ & $100 \%$ \\
Pest and rodent such as flies, mosquitoes and rats & $62(62 \%)$ & $21(21 \%)$ & $11(11 \%)$ & $6(6 \%)$ & $100 \%$ \\
\hline
\end{tabular}

Table 4. Showing effect of work environment and conditions on level of stress and burnout among the nurses.

\begin{tabular}{|c|c|c|c|c|c|c|}
\hline & Not at all & rarely & Sometimes & Often & Always & Total \\
\hline Do you feel run down and drained off physically and emotionally? & $1(1 \%)$ & $1(1 \%)$ & $48(48 \%)$ & $45(45 \%)$ & $5(5 \%)$ & $100(100 \%)$ \\
\hline $\begin{array}{l}\text { Do you find that you are prone to negative thinking about your } \\
\text { job? }\end{array}$ & $8(8 \%)$ & $69(69 \%)$ & $19(19 \%)$ & $4(4 \%)$ & $0(0 \%)$ & $100(100 \%)$ \\
\hline $\begin{array}{l}\text { Do you find that you are less sympathetic with people than } \\
\text { perhaps they deserve? }\end{array}$ & $7(7 \%)$ & $21(21 \%)$ & $67(67 \%)$ & $4(4 \%)$ & $1(1 \%)$ & $100(100 \%)$ \\
\hline $\begin{array}{l}\text { Do you find yourself getting easily irritated by small problems or } \\
\text { by your team or co-workers? }\end{array}$ & $8(8 \%)$ & $3(3 \%)$ & $86(86 \%)$ & $3(3 \%)$ & $0(0 \%)$ & $100(100 \%)$ \\
\hline Do you feel misunderstood or unappreciated by your co-workers? & $5(5 \%)$ & $11(11 \%)$ & $81(81 \%)$ & $3(3 \%)$ & $0(0 \%)$ & $100(100 \%)$ \\
\hline Do you feel you have no one to talk to? & $12(12 \%)$ & $61(61 \%)$ & $25(25 \%)$ & $2(2 \%)$ & $0(0 \%)$ & $100(100 \%)$ \\
\hline Do you feel that you are achieving less than you should? & & $11(11 \%)$ & $72(72 \%)$ & $13(13 \%)$ & $1(1 \%)$ & $100(100 \%)$ \\
\hline Do you feel an unpleasant level of pressure to succeed? & $3(3 \%)$ & $3(3 \%)$ & $54(54 \%)$ & $38(38 \%)$ & $2(2 \%)$ & $100(100 \%)$ \\
\hline Do you feel you are not getting what you want out of your job? & & $7(7 \%)$ & $56(56 \%)$ & $30(30 \%)$ & $2(2 \%)$ & $100(100 \%)$ \\
\hline Do you feel you are in a wrong ward? & $15(15 \%)$ & $67(67 \%)$ & $15(15 \%)$ & $3(3 \%)$ & $0(0 \%)$ & $100(100 \%)$ \\
\hline Is your job becoming more demanding on you? & $2(2 \%)$ & $3(3 \%)$ & $42(42 \%)$ & $46(46 \%)$ & $7(7 \%)$ & $100(100 \%)$ \\
\hline $\begin{array}{l}\text { Do you feel the hospital politics and protocols are frustrating your } \\
\text { ability to do a good job? }\end{array}$ & $2(2 \%)$ & $2(2 \%)$ & $27(27 \%)$ & $41(41 \%)$ & $\begin{array}{c}28 \\
(28 \%)\end{array}$ & $100(100 \%)$ \\
\hline $\begin{array}{l}\text { Do you feel there is more work to do than you practically have the } \\
\text { ability to do? }\end{array}$ & $1(1 \%)$ & $6(6 \%)$ & $43(43 \%)$ & $35(35 \%)$ & $\begin{array}{c}15 \\
(15 \%)\end{array}$ & $100(100 \%)$ \\
\hline $\begin{array}{l}\text { Do you feel you do not have time to do many of the important } \\
\text { things in doing a quality job? }\end{array}$ & $2(2 \%)$ & $4(4 \%)$ & $54(54 \%)$ & $35(35 \%)$ & $5(5 \%)$ & $100(100 \%)$ \\
\hline $\begin{array}{l}\text { Do you find that you do not have time to plan as much as you } \\
\text { would like to? }\end{array}$ & $2(2 \%)$ & $3(3 \%)$ & $58(58 \%)$ & $30(30 \%)$ & $7(7 \%)$ & $100(100 \%)$ \\
\hline
\end{tabular}

pondents indicating that they are rarely prone to negative thinking about their job and $67 \%$ rarely feel they are in the wrong ward. This means that despite the unfavourable work environment, work conditions are motivating. The socio-demographic characteristics revealed workers within the productive age with the younger nurses who form a greater percentage of the respondents being at the lower level of the professional ladder as presented on Table 5 where $64 \%$ of the nurse respondents fall between ages 25 and 40 years. Testing for relationship between nurses' cadre and stress and burnout was not significant, Table 6 p-value $0.530>0.05$, However there is an interesting discovery in that level of stress was higher among the Staff Nurses who have worked for only between 0 - 3 years, most of them are never married with no family social support, they recorded a mean score of 46.0000. This can be associated to the fact that they are new in the institution of care, in a new and strange environment especially when expectations are not met, stress increases. As they get older in the establishment they acclimatize, adjust to the rules and regulations of the institution and experience less stress. This is reflected in the level of stress among the Nursing Officers and Senior Nursing Officers who have a lesser mean stress score of 44.2222 and 45.0625 respectively. As the cadre rises, the nurses assume managerial roles, are accountable for a lot of subordinates and oversee both health related and administrative responsibilities, they experience more stress. Same is reflected in the stress mean score of Principal Nursing Officers and Chief Nursing Officers who recorded 46.7778 for PNO's and 47.2500 for CNO's as presented in Table 6, relationship between the nurses' 
Table 5. Biodata of respondent.

\begin{tabular}{|c|c|c|c|c|}
\hline & Frequency & Percent & Valid percent & Cumulative percent \\
\hline \multicolumn{5}{|l|}{ Age range of respondents } \\
\hline $21-30$ years & 25 & 25.0 & 25.0 & 25.0 \\
\hline $31-40$ years & 39 & 39.0 & 39.0 & 64.0 \\
\hline $41-50$ years & 23 & 23.0 & 23.0 & 87.0 \\
\hline Above 50 years & 13 & 13.0 & 13.0 & 100.0 \\
\hline Total & 100 & 100.0 & 100.0 & \\
\hline \multicolumn{5}{|c|}{ Sex distribution of respondents } \\
\hline Male & 1 & 1.0 & 1.0 & 1.0 \\
\hline Female & 99 & 99.0 & 99.0 & 100.0 \\
\hline Total & 100 & 100.0 & 100.0 & \\
\hline \multicolumn{5}{|c|}{ Respondents' marital status } \\
\hline Never married & 40 & 40.0 & 40.0 & 40.0 \\
\hline Married & 56 & 56.0 & 56.0 & 96.0 \\
\hline Divorced & 3 & 3.0 & 3.0 & 99.0 \\
\hline Widow & 1 & 1.0 & 1.0 & 100.0 \\
\hline Total & 100 & 100.0 & 100.0 & \\
\hline \multicolumn{5}{|c|}{ Number of children of respondents } \\
\hline 0 & 42 & 42.0 & 42.0 & 42.0 \\
\hline $1-2$ & 36 & 36.0 & 36.0 & 78.0 \\
\hline $3-4$ & 21 & 21.0 & 21.0 & 99.0 \\
\hline 5 and above & 1 & 1.0 & 1.0 & 100.0 \\
\hline Total & 100 & 100.0 & 100.0 & \\
\hline \multicolumn{5}{|c|}{ Level of education of respondents } \\
\hline Diploma in nursing & 49 & 49.0 & 49.0 & 49.0 \\
\hline BSc./Bed. & 36 & 36.0 & 36.0 & 85.0 \\
\hline MSc./Med. & 1 & 1.0 & 1.0 & 86.0 \\
\hline Specialty programme & 14 & 14.0 & 14.0 & 100.0 \\
\hline Total & 100 & 100.0 & 100.0 & \\
\hline \multicolumn{5}{|c|}{ Respondents currently pursuing an educational programme } \\
\hline Yes & 41.0 & 41.0 & 41 & 41 \\
\hline No & 59.0 & 59.0 & 59.0 & 100 \\
\hline \multicolumn{5}{|c|}{ Respondent's years of work experience in $\mathrm{UCH}$} \\
\hline $0-3$ & 41 & 41.0 & 41.0 & 41.0 \\
\hline $4-6$ & 27 & 27.0 & 27.0 & 68.0 \\
\hline $7-9$ & 15 & 15.0 & 15.0 & 83.0 \\
\hline $10-13$ & 7 & 7.0 & 7.0 & 90.0 \\
\hline$>13$ & 10 & 10.0 & 10.0 & 100.0 \\
\hline Total & 100 & 100.0 & 100.0 & \\
\hline \multicolumn{5}{|c|}{ Respondents' professional cadre } \\
\hline SN & 40 & 40.0 & 40.0 & 40.0 \\
\hline NO & 27 & 27.0 & 27.0 & 67.0 \\
\hline SNO & 16 & 16.0 & 16.0 & 83.0 \\
\hline $\mathrm{PNO}$ & 9 & 9.0 & 9.0 & 92.0 \\
\hline $\mathrm{CNO}$ & 8 & 8.0 & 8.0 & 100.0 \\
\hline Total & 100 & 100.0 & 100.0 & \\
\hline
\end{tabular}

Table 6. Relationship between the nurses' professional cadre and incidence of stress and burnout.

\begin{tabular}{|c|c|c|c|c|c|c|}
\hline & No. & Mean & Std. deviation & F value & $P$ value & Remark \\
\hline SN & 40 & 46.0000 & 4.70134 & \multirow{6}{*}{0.796} & \multirow{6}{*}{0.530} & \multirow{6}{*}{$\begin{array}{c}\text { Not } \\
\text { Significant }\end{array}$} \\
\hline NO & 27 & 44.2222 & 5.22813 & & & \\
\hline SNO & 16 & 45.0625 & 7.63735 & & & \\
\hline PNO & 9 & 46.7778 & 5.76146 & & & \\
\hline $\mathrm{CNO}$ & 8 & 47.2500 & 4.71320 & & & \\
\hline Total & 100 & 45.5400 & 5.47247 & & & \\
\hline
\end{tabular}

Using one way ANOVA to test stress by cadre at Alpha level $0.05, \mathrm{P}=0.530>0.05$ we fail to reject the hypothesis, which means there is no significant relationship between nurses' cadre and stress and burnout among them. 
professional cadre and incidence of stress and burnout. These findings are in line with Wu et al. (2007) [19] who also found that the burnout scores of women generally and from all dimensions of the burnout syndrome were higher among single members of the hospital staff. They stated further that this may be possible as the social support unit in which an individual is most likely to find shelter from the conflicts and difficulties of daily life is the family. Therefore, it was expected that married individuals would report lower levels of burnout syndrome than singles. In addition to illustrating a likely connection between nurse managers and staff nurse stressors [4], in her studies also reflected the demanding role of today's nurse managers who are often responsible for multiple patient care areas. This is also shown in Table 6, respondents who are Chief Nursing Officers (CNO) had the highest mean stress score of 47,2500 for relationship between the nurses' professional cadre and incidence of stress and burnout.

In another study, a general construct labeled "organizational support" exhibited the expected negative relationship with work exhaustion [20]. Similarly, social support from supervisors or colleagues demonstrated a negative association with work stress [21], as nurses felt more stress, they relied more on social support [4]. This is in agreement with the findings of some researchers who discovered that in management styles, relationship between staff nurses and nurse managers are particularly important when examining stress and burnout [22]. Table 7 shows these findings, where $75 \%$ of the nurses indicated that there is good human relation among every staff on their ward and 59\% said they can always go to their boss for assistance anytime they have a job or personal problem. Finally, it was discovered that group cohesion was higher and job stress lower when nurse managers used a more participative management style [4]. This is shown in Table 7 where $75 \%$ of the nurses indicated that there is good human relation among every staff on their ward which is indicative of group cohesion.

\section{Implications for Nurses}

The results of this study show that environmental factors have a significant effect on the level of stress of the nurses more than work conditions. This can be attributed to the fact that as the nurses indicate, there is good interpersonal relationship among them which may go a long way in reducing stress and burnout in relation to work conditions. The younger nurses who are new in the system and most of them never marry experience a higher level of stress and burnout.

When workers are happy, it is reflected in the quality of their work output. In order to promote quality nursing care in the University College Hospital, the Board of Management should look into the unconducive work environment as this may affect not only the nurses but also other workers and patients within the hospital who are not included in this study.

Based on the findings and the implication of the study for nursing, it is suggested that nurses should ensure that

Table 7. Showing factors relating to job related stress from work conditions.

\begin{tabular}{|c|c|c|c|c|c|c|}
\hline & SA & A & UD & $\mathrm{D}$ & $\mathrm{SD}$ & Total \\
\hline The roster is done to favour individual request & $3(3 \%)$ & $9(9 \%)$ & $8(8 \%)$ & $76(76 \%)$ & $4(4 \%)$ & $100 \%$ \\
\hline There is enough time to complete my work and report for the shift & $2(2 \%)$ & $11(11 \%)$ & $4(4 \%)$ & $79(79 \%)$ & $4(4 \%)$ & $100 \%$ \\
\hline I have enough time to go for my break on every shift & $0(0 \%)$ & $1(1 \%)$ & $4(4 \%)$ & $71(71 \%)$ & $24(24 \%)$ & $100 \%$ \\
\hline $\begin{array}{l}\text { There is adequate provision of functioning equipment to aid smooth } \\
\text { nursing care }\end{array}$ & $2(2 \%)$ & $38(38 \%)$ & $42(42 \%)$ & $9(9 \%)$ & $9(9 \%)$ & $100 \%$ \\
\hline I am confident that my job is secured & $6(6 \%)$ & $87(87 \%)$ & $4(4 \%)$ & $2(2 \%)$ & $1(1 \%)$ & $100 \%$ \\
\hline My salary and other incentives are up to standard & $1(1 \%)$ & $6(6 \%)$ & $8(8 \%)$ & $74(74 \%)$ & $11(11 \%)$ & $100 \%$ \\
\hline I am always promoted when due & $0(0 \%)$ & $8(8 \%)$ & $29(29 \%)$ & $55(55 \%)$ & $8(8 \%)$ & $100 \%$ \\
\hline $\begin{array}{l}\text { There is enough opportunity and encouragement to further my } \\
\text { education and for seminars }\end{array}$ & $4(4 \%)$ & $79(79 \%)$ & $6(6 \%)$ & $6(6 \%)$ & $5(5 \%)$ & $100 \%$ \\
\hline All amenities needed for my comfort at every shift are provided & $0(0 \%)$ & $0(0 \%)$ & $2(2 \%)$ & $37(37 \%)$ & $61(61 \%)$ & $100 \%$ \\
\hline There is adequate staff covering every shift & $0(0 \%)$ & $2(2 \%)$ & $1(1 \%)$ & $30(30 \%)$ & $67(67 \%)$ & $100 \%$ \\
\hline There is good human relation among every staff on the ward & $11(11 \%)$ & $75(75 \%)$ & $7(7 \%)$ & $4(4 \%)$ & $3(3 \%)$ & $100 \%$ \\
\hline $\begin{array}{l}\text { I can always go to my boss for assistance anytime I have a job or } \\
\text { personal problem }\end{array}$ & $8(8 \%)$ & $59(59 \%)$ & $23(23 \%)$ & $7(7 \%)$ & $3(3 \%)$ & $100 \%$ \\
\hline
\end{tabular}


the board of management of UCH provides means of promoting a conducive work environment by looking into the factors identified.

This study should be replicated in other units with less chronically ill patients who do not stay long in the hospital. It can also be replicated in other states in Nigeria, with a larger population.

\section{References}

[1] Salleh, M.R. (2008) Life Event, Stress and Illness. Malays Journal of Medical Sciences, 4, 9-18.

[2] Irving, J.A., Dobkin, P.L. and Park, J. (2009) Cultivating Mindfulness in Healthcare Professionals: A Review of Empirical Studies of Mindfulness-Based Stress Reduction (MBSR). Complementary Therapies in Clinical Practice, 15, 61-66. http://dx.doi.org/10.1016/j.ctcp.2009.01.002

[3] Robinson, M.D., Ode, S. and Hilmert, C. (2011) Regulated and Unregulated Forms of Cortisol Reactivity: A Dual Vulnerability Model. Psychosomatic Medicine, 73, 250-256. http://dx.doi.org/10.1097/PSY.0b013e3182099deb

[4] Jennings, B.M. (2009) Work Stress and Burnout among Nurses: Role of the Work Environment and Working Conditions, Health Care Consultant. In: Hughes, R.G., Ed., Patient Safety and Quality: An Evidence-Based Handbook for Nurses. Agency for Healthcare Research and Quality, Rockville. bmjennings@,cox.net

[5] Menzies, I.E.P. (1960) Nurses under Stress. International Nursing Review, 7, 9-16.

[6] Lukpata, F.E., Lukpata, O.H., Ndiok, A. and Mgbekem, M.A. (2013) Nurses Workplace Stress and patient Safety in General Hospital Calabar, Cross River State, Nigeria. International Professional Nursing Journal, 11, 87-92.

[7] Arafa, M.A. (2003) Predictors of Psychological Well-Being of Nurses in Alexandria, Egypt. International Journal of Nursing Practice, 9, 313-320. http://dx.doi.org/10.1046/j.1440-172X.2003.00437.x

[8] Ilhan, M.N., Tuzun, H., Ceyhan, M.N. and Aygun, R. (2005) Turning the Mirror on Ourselves: The Association between Burnout Syndrome and Personal Characteristics and Working Conditions of the Research Assistants Working in a University Hospital. Community and Physician, 20, 455-462.

[9] Rowe, J. (2003) The Suffering of the Healer. Nursing Forum, 38, 16-20. http://dx.doi.org/10.1111/j.0029-6473.2003.00016.x

[10] Abushaikha, L. and Saca-Hazboun, H. (2009) Job Satisfaction and Burnout among Palestinian Nurses. Eastern Mediterranean Health Journal, 15, 190-197.

[11] Khamisa, N., Oldenburg, B., Peltzer, K. and Ilic, D. (2015) Work Related Stress, Burnout, Job Satisfaction and General Health of Nurses. International Journal of Environmental Research and Public Health, 12, 652-666.

[12] Atencio, B.L., Cohen, J. and Gorenberg, B. (2003) Nurse Retention: Is It Worth It? Nursing Economics, 21, 262-268, 299, 259.

[13] Truby, B. (2009) Burnout Test. www.trubyachievements.com/..Stress Management/Burnout.html

[14] Ursin, H. and Eriksen, H.R. (2004) The Cognitive Activation Theory of Stress. Psychoneuroendocrinology, 29, 567592. http://dx.doi.org/10.1016/S0306-4530(03)00091-X

[15] International Council of Nurses (ICN) (2008)

[16] International Labour Organization (n.d.) Occupational Safety and Health. http://www.ilo.org/public/english/protection/safework/stress/nursing.htm

[17] Smith, S. (2013) Determining Sample Size: How to Ensure You Get the Correct Sample Size. E-Book (c) Qualtrics Online Sample.

[18] Suresh, K.P. and Chandrashekara, S. (2012) Sample Size Estimation and Power Analysis for Clinical Research Studies. Journal of Human Reproductive Science, 5, 7-13.

[19] Wu, S., Zhu, Z., Wang, Z., Wang, M. and Lan, Y. (2007) Relationship between Burnout and Occupational Stress among Nurses in China. Journal of Advanced Nursing, 59, 233-239. http://dx.doi.org/10.1111/j.1365-2648.2007.04301.x

[20] Blau, G., Tatum, D.S. and Ward-Cook, K. (2003) Correlates of Work Exhaustion for Medical Technologists. Journal Allied Health, 32, 148-157.

[21] Joiner, T.A. and Bartram, T. (2004) How Empowerment and Social Support Affect Australian Nurses' Work Stressors. Australian Health Review, 28, 56-64. http://dx.doi.org/10.1071/AH040056

[22] Laschinger, H.K., Finegan, J. and Shamian J. (2001). Impact of Structural and Psychological Empowerment on Job Strain in Nursing Work Settings. Expanding Kanter's Model. Journal of Nursing Administration, 1, 260-272. http://dx.doi.org/10.1097/00005110-200105000-00006 